\title{
Evidence for a variable silicate weathering feedback
}

\author{
DANIEL E. IBARRA ${ }^{1 *}$, KIMBERLY V. LAU ${ }^{2}$, JEREMY K. \\ CAVES RUGENNSTEIN ${ }^{3}$
}

${ }^{1}$ Department of Earth \& Planetary Science, University of California, Berkeley, Berkeley, California 94720-4767, USA (*dibarra@berkeley.edu)

${ }^{2}$ Department of Geology and Geophysics, University of Wyoming, Laramie, Wyoming 92071, USA

${ }^{3}$ Max Planck Institute for Meteorology, 20146 Hamburg, Germany

The rate of volcanic degassing, and therefore the input of carbon to Earth's oceans and atmosphere, has varied through time. Therefore, maintaining habitable conditions and balancing the exogenic carbon cycle over geologic time necessitates negative feedbacks between atmospheric $\mathrm{CO}_{2}$ and processes controlling the output fluxes. Continental silicate weathering and subsequent carbonate burial in the ocean, the primary output flux of carbon, has been hypothesized to impose such a negative feedback [1] and thus may be central in moderating the long-term carbon cycle over Earth history [2]. There still remains significant uncertainty in how the silicate weathering feedback has varied through time because: 1) modern solute flux observations are difficult to scale globally and require a space-for-time substitution using relationships with temperature and/or hydrologic changes [e.g., 3, 4], and 2) geologic carbon cycle models are primarily constrained by isotopic datasets rather than mass fluxes [5].

In this contribution I summarize evidence demonstrating that weatherability, the global silicate weathering flux at a given atmospheric $\mathrm{CO}_{2}$ level, and feedback strength, the slope of the weathering flux versus $\mathrm{CO}_{2}$ relationship, have both varied over geologic time due to the evolution of land plants, as well as paleogeography and subaerial lithologic variations. Here, I use timeseries observations of modern river chemistry [4] and reactive transport models [6] to infer the solution space for a variable silicate weathering feedback [e.g., 5, 7] as influenced by land plant evolution and lithologic changes. These relationships help place constraints on feedback parameterization used in the modeling of both the long-term ( $>1$ to 100 s of Myr) carbon cycle as well as the response of the system to short term (100s of kyrs) pertubations.

[1] Walker et al. (1981) J. Geophys Res: Oceans, 86, 9776-9782. [2] Berner (1992) Geochim. Cosmochim. Acta, 56, 3225-3231. [3] Li et al. (2016) Earth Planet. Sci. Lett., 443, 59-69. [4] Ibarra et al. (2016) Geochim. Cosmochim. Acta, 190, 265-293. [5] Caves Rugenstein et al. (2019) Nature, 571 (7763), 99-102. [6] Ibarra et al. (2019) Am. J. Sci., 319 (1), 1-43. [7] D'Antonio et al. (2020) Geology, 48, 29-33. 